\title{
Training distribution during a Paralympic cycle for a multiple swimming champion with paraplegia: a case report
}

\author{
Julia Kathrin Baumgart $^{1 *}$, Espen Tønnessen ${ }^{2}$, Morten Eklund ${ }^{3}, \varnothing_{\text {yvind Sandbakk }}{ }^{1}$ \\ ${ }^{1}$ Centre for Elite Sports Research, Department of Neuromedicine and Movement Science, \\ Norwegian University of Science and Technology, Trondheim, Norway \\ ${ }^{2}$ Kristiania University College, Oslo, Norway \\ ${ }^{3}$ Norwegian Top Sports Centre, Division of South-west Norway, Stavanger, Norway \\ * Correspondence \\ Julia Kathrin Baumgart \\ Centre for Elite Sports Research \\ Smistadgrenda 11 \\ 7026 Trondheim \\ Email: julia.k.baumgart@ntnu \\ Telephone: +4748436206
}

\begin{abstract}
Purpose: To describe the training volume, intensity distribution and use of swimming styles during a Paralympic cycle in a multiple swimming champion with paraplegia.

Methods: The female Paralympic swimmer was 23-26 years, had a body-mass of 60-62 kg and a body-height of $174 \mathrm{~cm}$. She has a spinal cord injury at the Th6 level, competed in the S5/SB4 Para swimming classes and uses a wheelchair for mobility. Training time, as well as distance in the different intensity zones and swimming styles were registered with the "workouts for swim coaches" software throughout a full Paralympic cycle.

Results: The Para swimmer performed a total of 388, 524, 471 and 656 annual hours of swimming, corresponding to 1126, 1504, 1463 and $1993 \mathrm{~km}$ in the 2012/13, 2013/14, 2014/15 and 2015/16 seasons. In addition, she performed 1-3 weekly dry-land strength sessions and 46 weekly dry-land basic skill sessions. She conducted 91-94\% of the swimming distance in each macro cycle at low intensity, $2-4 \%$ at moderate intensity and 3-6\% at high intensity. She performed $78-84 \%$ of the swimming distance in each macro cycle in the freestyle swimming technique and the remaining 16-22\% in the backstroke, breaststroke, and butterfly techniques. Conclusion: This case study exemplifies how a female Paralympic swimmer with paraplegia progressed her training in the seasons leading up to the Paralympic Games, reaching an annual training distance of $2000 \mathrm{~km}$, which is similar to that of able-bodied swimmers.
\end{abstract}

Keywords: intensity distribution, swimming distance, Para swimmer, disability, spinal cord injury 


\section{Training of a Para swimming champion}

\section{Introduction}

All the way since the first Paralympic Games in Rome in 1960, Para swimming has been one of the sports with the largest number of events and participating athletes (www.paralympic.org/swimming/about). Para swimming events range from 50 to $400 \mathrm{~m}$ (i.e. racing times from $\sim 30 \mathrm{sec}$ to $7 \mathrm{~min}$ ) and are performed in the breaststroke, backstroke, butterfly and freestyle techniques. Depending on the type of impairment, race distance and style, race times are 7 to $300 \%$ slower compared to able-bodied swimmers (https://www.paralympic.org/swimming/records). Thus, to allow for fair competitions in Para swimming, athletes compete in ten classes for physically impaired athletes (S1-S10, from the most to the least impaired), three classes for visually impaired athletes (S11-S13, from most to least impaired) and one class for intellectually impaired athletes (S14) (www.paralympic.org/swimming/classification).

Able-bodied world-class swimmers have reported annual training volumes between 800 to 1200 hours, of which 600-900 hours are spent in the water with a swimming distance in the range of 1500-3600 km. ${ }^{1,2}$ These are amongst the highest annual training hours reported for endurance athletes, which may partly explained by the need for adapting the technique and cardio-respiratory system to moving in a different environment (i.e. water) with the body in a supine position. In addition, high training loads are tolerated by swimmers through the relatively low mechanical impact on the muscles, bones and joints. ${ }^{3}$ Among world-class Para swimmers, the weekly training distance is reported to be approximately half $\left(15-35 \mathrm{~km} \cdot \mathrm{week}^{-}\right.$ $\left.{ }^{1}\right)^{4,5}$ compared to able-bodied swimmers $\left(40-70 \mathrm{~km} \cdot \mathrm{week}^{-1}\right){ }^{2,6}$ In line with this, a case study on a multiple Paralympic swimming champion with cerebral palsy reported an annual training distance of $1500 \mathrm{~km}^{7}$, which is at the lower end of the range of what was reported in elite ablebodied swimmers. Para swimmers who sit in a wheelchair use their upper body both for daily life activities and during training, which may increase the need for recovery between sessions and thereby reduce training volumes. In addition, athletes with paraplegia display greater heat storage compared to able-bodied athletes during recovery from upper-body exercise, indicating impaired thermoregulation. ${ }^{8}$ As such, the need for recovery may be further increased and training volumes reduced in Para swimmers with paraplegia who use a wheelchair for mobility.

The few studies done on able-bodied short- and middle-distance swimmers indicate that $~ 80$ $85 \%$ of the endurance training time/ distance is performed at low-intensity (LIT; i.e. below the aerobic threshold) and $\sim 5-15 \%$ at moderate-intensity (MIT; i.e. below the anaerobic threshold), whereas around $\sim 5-10 \%$ are performed at high-intensity (HIT). ${ }^{1,6,9,10}$ The high amount of LIT even in short-distance swimmers, who compete at supra-maximal intensities, enables many hours of swimming with a good technique and high propulsive efficiency, which is considered critical to swimming success. ${ }^{11}$ Currently, no studies have reported the annual intensity distribution or use of swimming styles among Para swimmers.

Therefore, the purpose of this case study was to describe the training volume, intensity distribution and use of swimming styles during a Paralympic cycle in a multiple swimming champion with paraplegia who is a wheelchair user. 


\section{Methods}

Participant

The female Paralympic swimmer featured in this case report was 23-26 years old, had a bodymass of 60-62 kg and a body-height of $174 \mathrm{~cm}$, and competed in the S5/SB4 classes (for an explanation on the Para swimming classes, see www.paralympic.org/swimming/classification). She has a spinal cord injury due to a surgical error at the level of Th 6 at the age of 19, i.e. 4 years prior to the Paralympic cycle investigated in this case report. She competed in swimming from a young age up until her injury and resumed swimming 3 months after her injury. Since then she won 2 gold and 2 silver medals at the Paralympic Games in London and 2 gold, 1 silver and 2 bronze medals at the Paralympic Games in Rio 2016, as well as numerous medals at several European and World Championships. The Norwegian Data Registry approved the study (ID-233565), and the participant provided written informed consent to voluntarily take part in the study and to publishing her indirectly identifiable data and case description.

\section{Methodology}

Training data from the 2012/2013 to the 2015/2016 season was collected from the athlete's training log which was registered in the "workouts for swim coaches" software (Big Fish Software, Zagreb, Croatia). Training load was determined by annual and weekly training hours/swimming distance, and training intensity. The modified session-goal approach ${ }^{12}$ was used to quantify training intensity based on the perceived intensity of the session, the workload applied and the \% of peak heart rate (Figure 1). The swimmer's peak heart rate was 192 beats $\min ^{-1}$, which was the highest value recorded during all-out training sessions. In selected training sessions, blood lactate concentration was measured by a Lactate Pro 1 analyzer (Arkray KDK, Japan) to ensure that the target intensity was correct during the training sessions. Furthermore, swimming styles used during each swimming session were registered in the "workouts for swim coaches" software. Training plans were examined, and the athlete, coach and team physiologist were interviewed to get detailed information on sessions employed in each intensity zone (Figure 1) and typical content in preparation, altitude camp and tapering training weeks (Figure 2).

\section{Statistical analyses}

The data is presented as total annual hours of swimming and total annual swimming distance, as well as swimming distance performed within the different intensity-zones or swimming styles for each macro cycle $\left(\right.$ meters $\left.^{\cdot} \mathrm{week}^{-1}\right)$. All statistical analyses were carried out in Microsoft Excel (Microsoft, Redmond, WA, USA). 


\begin{tabular}{|c|c|c|c|c|c|c|c|}
\hline & $\begin{array}{l}\text { Intensity } \\
\text { zone }\end{array}$ & $\begin{array}{l}\% \text { of Peak } \\
\text { heart rate }\end{array}$ & $\begin{array}{l}\text { Blood lactate } \\
\left(\mathrm{mmol} \cdot \mathrm{L}^{-1}\right)\end{array}$ & RPE & $\begin{array}{l}\text { Time to } \\
\text { exhaustion }\end{array}$ & Session goal pace & Example sessions \\
\hline \multirow{4}{*}{$\begin{array}{l}\text { Race } \\
\text { pace }\end{array}$} & $\mathrm{I}-8$ & - & - & - & $15 \mathrm{~s}$ & $15 \mathrm{~m} / 25 \mathrm{~m}$ speed $(10-20 \mathrm{~s})$ & $4 \mathrm{x}(6 \times 20 \mathrm{~m}$ breaststroke, $@ 2 \mathrm{~min}, \mathrm{TT}=17 \mathrm{~s}), \mathrm{SB}=200 \mathrm{~m}$ freestyle, I-1 \\
\hline & I-7 & - & Peak & $19-20$ & $1 \mathrm{~min}$ & $35 \mathrm{~m} / 100 \mathrm{~m}$ speed $(45-90 \mathrm{~s})$ & Alternative a) 20x25 m breast, @1:30 min, TT=21s \\
\hline & & & & & & & $\begin{array}{l}\text { Alternative b) } 6 \times(2 \times 50 \mathrm{~m} \text { breast, @2 min, TT=48-50s), SB=300m } \\
\text { freestyle, I-1 }\end{array}$ \\
\hline & $\mathrm{I}-6$ & - & $>6$ & $19-20$ & $4 \mathrm{~min}$ & $200 \mathrm{~m} / 400 \mathrm{~m}$ speed $(3-5: 30 \mathrm{~min})$ & $\begin{array}{l}\text { 6x }(1 \times 75 \mathrm{~m} \text { breaststroke, I- } 6, \mathrm{TT}=1: 17-1: 19 \mathrm{~min}+1 \times 75 \mathrm{~m} \text { crawl, I-1, } \\
\mathrm{TT}=1: 20 \mathrm{~min}), \mathrm{SB}=1 \mathrm{~min}\end{array}$ \\
\hline \multirow[t]{2}{*}{ HIT } & $\mathrm{I}-5$ & $>92$ & $4-5.9$ & $19-20$ & $10 \mathrm{~min}$ & $800 \mathrm{~m}$ speed $(10-12 \mathrm{~min})$ & $\begin{array}{l}4 \mathrm{x}(1 \mathrm{x} 100 \mathrm{~m} \text { breaststroke, @: } 2: 30, \mathrm{TT}=1: 48+2 \times 50 \mathrm{~m} \text { breaststroke, } \\
@ 1: 30, \mathrm{TT}=49 \mathrm{~s}+4 \mathrm{x} 25 \mathrm{~m} \text { breaststroke, @1 min, TT=22s), SB=1:30min }\end{array}$ \\
\hline & $\mathrm{I}-4$ & $88-92$ & 2.5-3.9 & $17-18$ & $30 \mathrm{~min}$ & $1500 / 2000 \mathrm{~m}$ speed $(20-30 \mathrm{~min})$ & $\begin{array}{l}2 \times 200 \mathrm{~m} \text { breaststroke, @4:30 min, TT=4:00-4:05 + 4x100 m } \\
\text { breaststroke, @:2:30 TT=1:55+8x50 m breaststroke, @1:30,TT=50 }\end{array}$ \\
\hline MIT & $\mathrm{I}-3$ & $82-87$ & $1.7-2.4$ & $15-17$ & $60 \mathrm{~min}$ & $3000 / 4000 \mathrm{~m}$ speed $(45-60 \mathrm{~min})$ & 30x100m freestyle, @1:50,TT=1:30 \\
\hline \multirow[t]{2}{*}{ LIT } & $\mathrm{I}-2$ & $75-82$ & $1.2-1.6$ & $12-14$ & $3 \mathrm{hrs}$ & & $\begin{array}{l}\text { 10x (100 m medley, @2:20, TT=1:50min + } 200 \mathrm{~m} \text { freestyle, @3:45, } \\
\text { TT=3:15) }\end{array}$ \\
\hline & $\mathrm{I}-1$ & $60-74$ & $<1.2$ & $8-11$ & & & $\begin{array}{l}4 \times 400 \mathrm{~m} \text { freestyle, @:7:00; TT }=6: 20 \mathrm{~min}+3 \times 300 \mathrm{~m} \text { freestyle, @5:30; } \\
\mathrm{TT}=4: 50 \mathrm{~min}+2 \times 200 \mathrm{~m} \text { freestyle, @3:45, TT=2:20 + 1x100 m freestyle, } \\
\mathrm{TT}=1: 35\end{array}$ \\
\hline
\end{tabular}

Figure 1 - Load surveillance (heart rate, blood lactate, and RPE), time to exhaustion, session goal pace, as well as example sessions within each of the intensity zones for a multiple Paralympic swimming champion of the S5/SB4 Class. HIT indicates high-intensity training; LIT, low-intensity training; MIT, moderate-intensity training; RPE, rating of perceived exertion; SB, series break; TT, target time; @, start time. 
Training of a Para swimming champion

\begin{tabular}{|c|c|c|c|c|c|c|c|}
\hline $\mathbf{A}$ & Monday & Tuesday & Wednesday & Thursday & Friday & Saturday & Sunday \\
\hline Early Morning & Low intensity & $\begin{array}{c}\text { Low intensity } \\
+\mathrm{I}-8\end{array}$ & Low intensity & $\begin{array}{c}\text { Low intensity } \\
+\mathrm{I}-8\end{array}$ & Low intensity & $\begin{array}{l}\text { High intensity } \\
(600 \mathrm{~m}, \mathrm{I}-7)\end{array}$ & \multirow{6}{*}{ Free } \\
\hline & $\begin{array}{l}4500 \mathrm{~m} \\
1: 45 \mathrm{hrs}\end{array}$ & $\begin{array}{l}4500 \mathrm{~m} \\
1: 45 \mathrm{hrs}\end{array}$ & $\begin{array}{l}4000 \mathrm{~m} \\
1: 45 \mathrm{hrs}\end{array}$ & $\begin{array}{l}4500 \mathrm{~m} \\
1: 45 \mathrm{hrs}\end{array}$ & $\begin{array}{l}4500 \mathrm{~m} \\
1: 45 \mathrm{hrs}\end{array}$ & $\begin{array}{c}5000 \mathrm{~m} \\
2 \mathrm{hrs}\end{array}$ & \\
\hline Late Morning & $\begin{array}{l}\text { Strength } \\
1: 10 \mathrm{hrs}\end{array}$ & & $\begin{array}{l}\text { Strength } \\
1: 10 \mathrm{hrs}\end{array}$ & & $\begin{array}{l}\text { Strength } \\
1: 10 \mathrm{hrs}\end{array}$ & & \\
\hline $\begin{array}{l}\text { Straight before } \\
\text { afternoon session }\end{array}$ & $\begin{array}{c}\text { Basic skills } \\
30 \mathrm{~min}\end{array}$ & $\begin{array}{c}\text { Basic skills } \\
30 \mathrm{~min}\end{array}$ & \multirow{3}{*}{ Free } & $\begin{array}{c}\text { Basic skills } \\
30 \mathrm{~min}\end{array}$ & $\begin{array}{c}\text { Basic skills } \\
30 \mathrm{~min}\end{array}$ & \multirow{3}{*}{ Free } & \\
\hline \multirow[t]{2}{*}{ Afternoon } & $\begin{array}{l}\text { Medium intensity } \\
(1800-2500 \mathrm{~m} \text {, } \\
\mathrm{I}-2 / 3)\end{array}$ & $\begin{array}{c}50-\& 100-\mathrm{m} \\
\text { race pace } \\
(600 \mathrm{~m}, \mathrm{I}-4 / 5)\end{array}$ & & $\begin{array}{c}\text { High intensity } \\
(800-1000 \mathrm{~m}, \\
\mathrm{I}-4 / 5)\end{array}$ & Low intensity & & \\
\hline & $\begin{array}{c}5000 \mathrm{~m} \\
2 \mathrm{hrs} \\
\end{array}$ & $\begin{array}{c}4000 \mathrm{~m} \\
2 \mathrm{hrs}\end{array}$ & & $\begin{array}{c}4000 \mathrm{~m} \\
2 \mathrm{hrs}\end{array}$ & $\begin{array}{r}5500 \mathrm{~m} \\
2 \mathrm{hrs} \\
\end{array}$ & & \\
\hline B & Monday & Tuesday & Wednesday & Thursday & Friday & Saturday & Sunday \\
\hline \multirow[t]{2}{*}{ Early Morning } & $\begin{array}{c}\text { Low intensity } \\
+\mathrm{I}-8\end{array}$ & Low intensity & $\begin{array}{c}\text { Low intensity } \\
+\mathrm{I}-8\end{array}$ & Low intensity & Low intensity & $\begin{array}{l}\text { Medium intensity } \\
(1000-1200 \mathrm{~m}, \mathrm{I}-3)\end{array}$ & Low intensity \\
\hline & $\begin{array}{c}4500 \mathrm{~m} \\
2 \mathrm{hrs} \\
\end{array}$ & $\begin{array}{c}5000 \mathrm{~m} \\
2 \mathrm{hrs} \\
\end{array}$ & $\begin{array}{c}4500 \mathrm{~m} \\
2 \mathrm{hrs} \\
\end{array}$ & $\begin{array}{c}5500 \mathrm{~m} \\
2 \mathrm{hrs} \\
\end{array}$ & $\begin{array}{c}5000 \mathrm{~m} \\
2 \mathrm{hrs}\end{array}$ & $\begin{array}{c}4500 \mathrm{~m} \\
2 \mathrm{hrs} \\
\end{array}$ & $\begin{array}{c}5000 \mathrm{~m} \\
2 \mathrm{hrs} \\
\end{array}$ \\
\hline Late Morning & $\begin{array}{c}\text { Strength } \\
1 \mathrm{hr}\end{array}$ & & & & $\begin{array}{c}\text { Strength } \\
1 \mathrm{hr}\end{array}$ & & \\
\hline $\begin{array}{l}\text { Straight before } \\
\text { afternoon session }\end{array}$ & $\begin{array}{c}\text { Basic skills } \\
30 \mathrm{~min}\end{array}$ & $\begin{array}{c}\text { Basic skills } \\
30 \mathrm{~min}\end{array}$ & $\begin{array}{c}\text { Basic skills } \\
30 \mathrm{~min}\end{array}$ & \multirow{3}{*}{ Free } & $\begin{array}{c}\text { Basic skills } \\
30 \mathrm{~min}\end{array}$ & $\begin{array}{c}\text { Basic skills } \\
30 \mathrm{~min}\end{array}$ & $\begin{array}{c}\text { Basic skills } \\
30 \mathrm{~min}\end{array}$ \\
\hline \multirow[t]{2}{*}{ Afternoon } & Low intensity & $\begin{array}{l}\text { Medium intensity } \\
(800-1000 \mathrm{~m}, \mathrm{I}-3)\end{array}$ & High intensity & & $\begin{array}{c}\text { Low intensity } \\
+\mathrm{I}-8\end{array}$ & $\begin{array}{l}\text { High intensity } \\
(400-600 \mathrm{~m}, \mathrm{I}-7)\end{array}$ & Low intensity \\
\hline & $\begin{array}{c}4000 \mathrm{~m} \\
2 \mathrm{hrs} \\
\end{array}$ & $\begin{array}{c}4500 \mathrm{~m} \\
2 \mathrm{hrs}\end{array}$ & $\begin{array}{c}4000 \mathrm{~m} \\
2 \mathrm{hrs} \\
\end{array}$ & & $\begin{array}{c}4000 \mathrm{~m} \\
2 \mathrm{hrs} \\
\end{array}$ & $\begin{array}{c}4500 \mathrm{~m} \\
2 \mathrm{hrs}\end{array}$ & $\begin{array}{c}4000 \mathrm{~m} \\
2 \mathrm{hrs} \\
\end{array}$ \\
\hline C & Day 7 & Day 6 & Day 5 & Day 4 & Day 3 & Day 2 & Day 1 \\
\hline \multirow[t]{2}{*}{ Early Morning } & Low intensity & Low intensity & Low intensity & $\begin{array}{l}\text { Medium intensity } \\
(400-600 \mathrm{~m}, \mathrm{I}-2-4)\end{array}$ & Low intensity & $\begin{array}{l}\text { High intensity } \\
(200 \mathrm{~m}, \mathrm{I}-6-7)\end{array}$ & Low intensity \\
\hline & $\begin{array}{l}3500 \mathrm{~m} \\
1: 30 \mathrm{hrs} \\
\end{array}$ & $\begin{array}{l}3500 \mathrm{~m} \\
1: 30 \mathrm{hrs} \\
\end{array}$ & $\begin{array}{c}3000 \mathrm{~m} \\
1 \mathrm{hr} \\
\end{array}$ & $\begin{array}{l}3500 \mathrm{~m} \\
1: 30 \mathrm{hrs}\end{array}$ & $\begin{array}{l}3000 \mathrm{~m} \\
1: 30 \mathrm{hrs}\end{array}$ & $\begin{array}{c}2500 \mathrm{~m} \\
1 \mathrm{hr}\end{array}$ & $\begin{array}{r}2500 \mathrm{~m} \\
45 \mathrm{~min} \\
\end{array}$ \\
\hline Late Morning & & $\begin{array}{c}\text { Strength } \\
45 \mathrm{~min}\end{array}$ & & & & & \\
\hline $\begin{array}{l}\text { Before afternoon } \\
\text { session }\end{array}$ & $\begin{array}{c}\text { Basic } \\
\text { skills } \\
30 \mathrm{~min} \\
\end{array}$ & $\begin{array}{c}\text { Basic } \\
\text { skills } \\
30 \mathrm{~min} \\
\end{array}$ & \multirow{3}{*}{ Free } & $\begin{array}{c}\text { Basic } \\
\text { skills } \\
30 \mathrm{~min} \\
\end{array}$ & \multirow{3}{*}{ Free } & $\begin{array}{c}\text { Basic } \\
\text { skills } \\
30 \mathrm{~min} \\
\end{array}$ & \multirow{3}{*}{ Free } \\
\hline \multirow[t]{2}{*}{ Afternoon } & $\begin{array}{l}\text { Medium intensity } \\
(600-800 \mathrm{~m}, \\
\mathrm{I}-2-4)\end{array}$ & $\begin{array}{c}50-\& 100-\mathrm{m} \\
\text { race pace } \\
(200-300 \mathrm{~m}, \mathrm{I}-5)\end{array}$ & & $\begin{array}{l}\text { High intensity } \\
(200-300 \mathrm{~m}, \\
\mathrm{I}-7)\end{array}$ & & Low intensity & \\
\hline & $\begin{array}{c}3000 \mathrm{~m} \\
1 \mathrm{hr}\end{array}$ & $\begin{array}{c}2400 \mathrm{~m} \\
1 \mathrm{hr}\end{array}$ & & $\begin{array}{r}2000 \mathrm{~m} \\
45 \mathrm{~min}\end{array}$ & & $\begin{array}{r}2000 \mathrm{~m} \\
45 \mathrm{~min} \\
\end{array}$ & \\
\hline
\end{tabular}

Figure 2 - Examples of (A) a typical preparation period week, (B) a typical altitude training camp week (toughest week in the middle of the camp), and (C), a typical training week when tapering for a major international competition including focus, distance, and time of swimming sessions for a multiple Paralympic swimming champion of the S5/SB4 class. For the mediumand high-intensity sessions, the numbers at the bottom of the boxes indicate total session duration and distance, which is a combination of the distance covered at medium and high intensity but also includes the distance covered for active recovery spent in intensities zones I1 and I-2. Dry-land basic skill sessions are used to develop fundamental skills such as flexibility, balance, and coordination through exercises targeting muscles and joints that are important for force generation and sport-specific movements in swimming. See Figure 1 for example sessions in the different intensity zones (I-1 to I-8). 


\section{Results}

The Para swimmer performed a total of 388, 524, 471 and 656 annual hours of swimming, corresponding to 1126, 1504, 1463 and $1993 \mathrm{~km}$ in the 2012/13, 2013/14, 2014/15 and 2015/16 seasons (Figure 3). In addition, she conducted 1-3 weekly dry-land strength sessions and 4-6 weekly dry-land basic skill sessions. She performed $>90 \%$ of the total swimming distance as LIT, 2-4\% at MIT, and 3-6\% at HIT or race pace (Figure 3A), with example sessions for each of the intensity zones provided in Figure 1 . She conducted $78-84 \%$ of the swimming distance in each macro cycle using freestyle swimming, with the remaining 16-22\% being executed in the backstroke, breaststroke, butterfly and medley technique (Figure 3B). Whereas training distance was lower in the first macro cycle compared to the second and third macro cycle in the 2012/2013 and the 2013/2014 seasons, training distance in the first macro cycle is higher and varies less across cycles in the 2014/2015 and 2015/2016 seasons (Figure 3A-B). Weekly swimming distance varied considerably within each macro cycle (Figure 4A-D). In Figure 2, typical preparation period, altitude training and tapering weeks are exemplified.

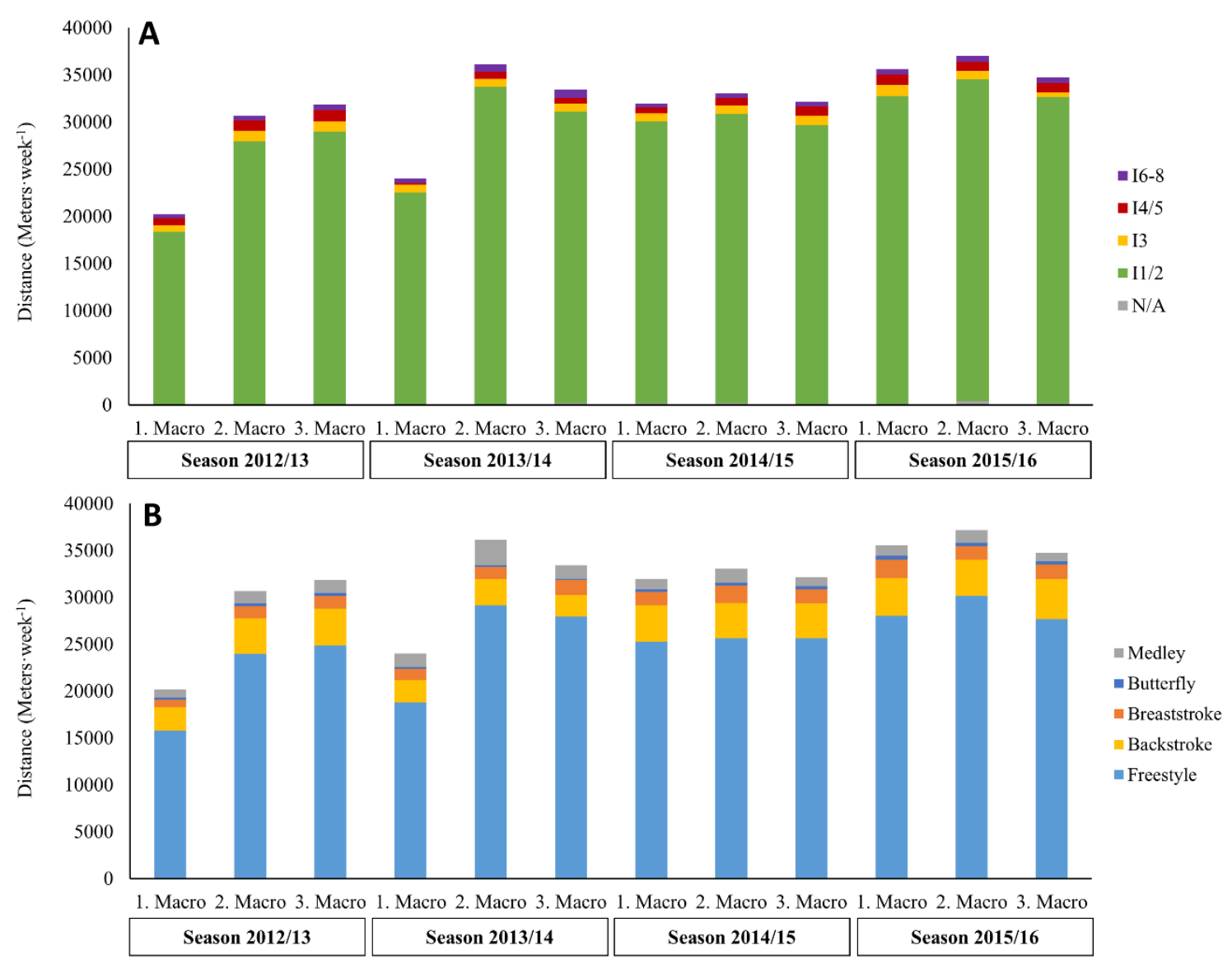

Figure 3 - Distance per week (in meters) divided into training-intensity zones (A) and swimming style (B) within each macro cycle. 


\section{Training of a Para swimming champion}
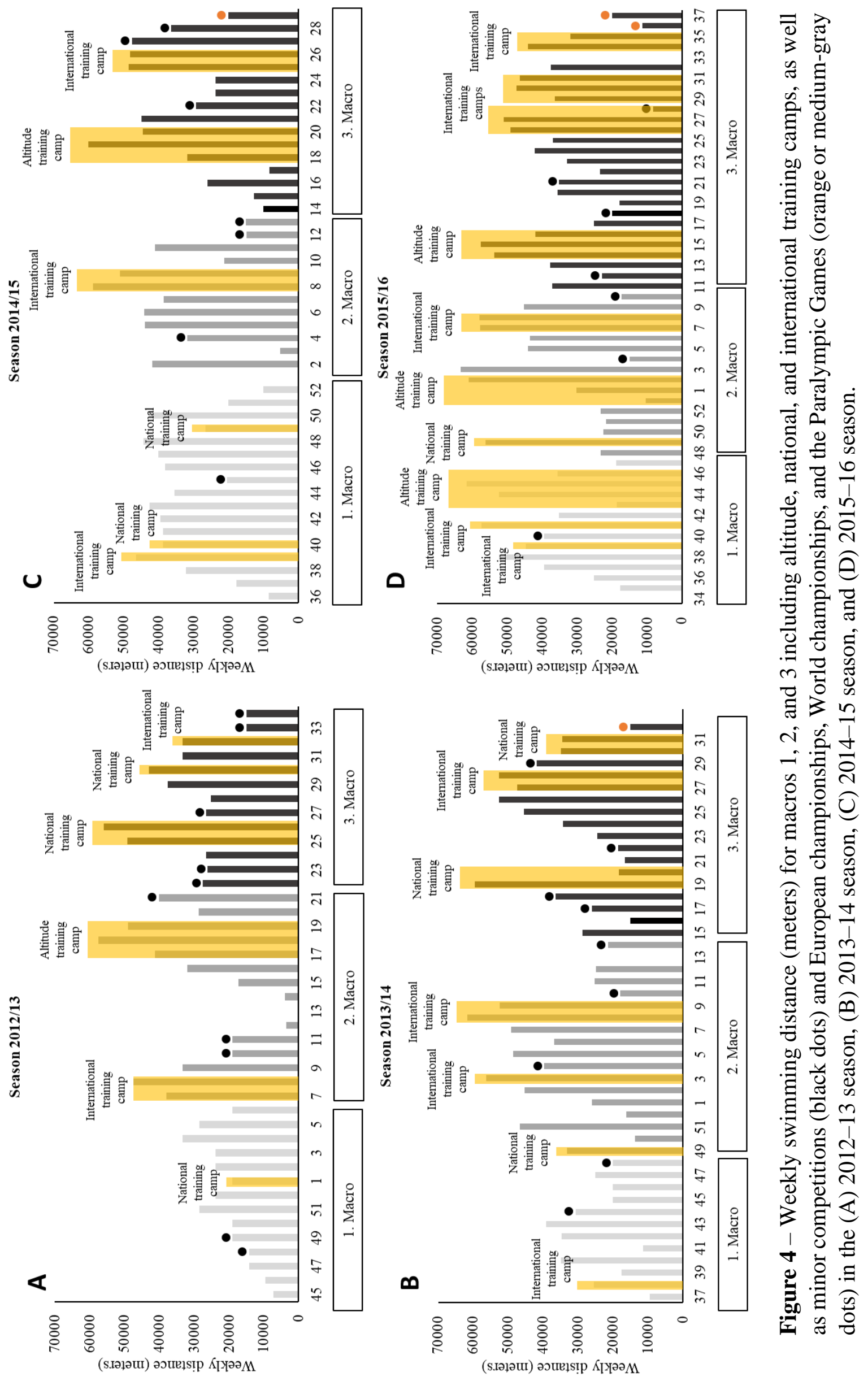


\section{Training of a Para swimming champion}

\section{Discussion}

In this case-report, we described the training volume, intensity distribution and use of swimming styles during a Paralympic cycle of a multiple Paralympic swimming champion with paraplegia. The Para swimmer gradually increased her swimming distance year-by-year to exhibiting an annual distance of $2000 \mathrm{~km}$ in the season leading up to the Paralympic Games. This is exceptionally high, when keeping in mind that she solely used her upper body during both training and for wheelchair propulsion in daily life. Above $90 \%$ of her training was LIT interspersed with 3-5 weekly MIT or HIT/race pace sessions, with around $80 \%$ of the training distance swum in the freestyle technique. In addition, she performed 1-3 weekly strength training and 4-6 weekly dry-land basic skill sessions to facilitate technical development and injury prevention.

The swimming distance of approximately $2000 \mathrm{~km}$ in the last year leading up to the Paralympic Games in Rio 2016 reported in this case study is the highest ever reported for a Para swimmer and comparable to the volumes performed among elite able-bodied short- and middle-distance swimmers. ${ }^{1,2}$ To reach this level, the athlete had a relatively rapid increase in swimming distance from 2012 to 2016 which is mainly attributed to her training progression and the longer season in 2016, although a small portion of the increase may also be influenced by the more systematic (and accurate) training recordings in the 2016 season. The distribution of swimming distance across weeks is also in line with what was shown in elite able-bodied swimmers ${ }^{1,13}$ and shows a unique long-term ability to balance weeks with high and low training loads to avoid injuries/periods of sickness. Speculatively, the Para swimmer investigated in this case report needed to be even more aware than her able-bodied counterparts in balancing her training load, due to the increased recovery demands after exercise sessions when using her upper-body both during training and for daily life activities. In addition, the relatively large amounts of dry-land training might have been important to reduce the risk of injuries as well as having direct positive effects on swimming performance. ${ }^{14}$ Overall, these data provide a framework for understanding the training required among Para swimmers aiming at winning medals at the world championships and Paralympic games.

In line with able-bodied swimmers, ${ }^{1,6}$ around $91-94 \%$ of the training was spent at LIT, enabling a large training load of swimming while maintaining a relevant and efficient technique. In addition, the regular MIT and HIT/ race-pace sessions ensure complementary stimuli of high importance for performance-development. ${ }^{15}$ The high volumes of LIT might also explain why the Para swimmer performed around $78-84 \%$ of her training in the freestyle technique, reflecting the lower technical demands compared to the other swimming techniques, despite competing and winning medals in the breaststroke, backstroke, medley and butterfly competitions. Still, specific training in the competing swimming styles, and especially at HIT and race pace, is important for developing the technique-specific physiological capacities as well as technical abilities, mental skills, and optimal pacing strategies. The Para swimmer in this case study used specific HIT and race-pace sessions and minor domestic and international competitions for developing these capacities and skills.

\section{Practical Applications}

This case study exemplifies that a Paralympic swimmer, who has increased recovery demands after exercise and uses a wheelchair for mobility, can tolerate and respond positively to similar training volumes as world class able-bodied swimmers. However, a gradual increase in training volume is required to tolerate such high training loads and avoid injuries. This is important 
knowledge for Para swimmers and their coaches aiming for medaling at international Para swimming competitions.

\section{Conclusion}

The female Paralympic swimmer with paraplegia examined here progressed her training yearby-year in the seasons leading up to the Paralympic Games, reaching an annual training distance of $2000 \mathrm{~km}$. This is similar to training volumes of able-bodied elite swimmers and the highest ever reported in a Para-swimmer. She performed $91-94 \%$ of the swimming distance at LIT interspersed by 3-5 weekly MIT/HIT/race-pace sessions and regular dry-land basic skill sessions to improve strength and facilitate technical development and injury prevention.

\section{Acknowledgements}

We would like to thank the participant for her willingness to share her data and personal views on her training. This study was funded by the Centre for Elite Sports Research, Department of Neuromedicine and Movement Science at the Norwegian University of Science and Technology in Trondheim, Norway. 


\section{References}

1. Baldassarre R, Bonifazi M, Meeusen R, Piacentini MF. The Road to Rio: A Brief Report of Training-Load Distribution of Open-Water Swimmers During the Olympic Season. Int J Sports Physiol Perform. 2019;14(2):260-264.

2. Pollock S, Gaoua N, Johnston MJ, Cooke K, Girard O, Mileva KN. Training regimes and recovery monitoring practices of elite British swimmers. Journal of sports science \& medicine. 2019;18(3):577.

3. Duncan CS, Blimkie CJ, Cowell CT, Burke S, Briody JN, Giles-Howman R. Bone mineral density in adolescent female athletes: relationship to exercise type and muscle strength. 2002.

4. Fulton SK, Pyne DB, Hopkins WG, Burkett B. Training characteristics of paralympic swimmers. Journal of strength and conditioning research / National Strength \& Conditioning Association. 2010;24(2):471-478.

5. Pelayo P, Sidney M, Moretto P, Wille F, Chollet D. Stroking parameters in top level swimmers with a disability. Med Sci Sports Exerc. 1999;31(12):1839-1843.

6. Pla R, Le Meur Y, Aubry A, Toussaint JF, Hellard P. Effects of a 6-Week Period of Polarized or Threshold Training on Performance and Fatigue in Elite Swimmers. Int J Sports Physiol Perform. 2019;14(2):183-189.

7. Puce L, Marinelli L, Pierantozzi E, et al. Training methods and analysis of races of a top level Paralympic swimming athlete. Journal of exercise rehabilitation. 2018;14(4):612-620.

8. Price MJ, Campbell IG. Thermoregulatory and physiological responses of wheelchair athletes to prolonged arm crank and wheelchair exercise. International journal of sports medicine. 1999;20(7):457-463.

9. Mujika I, Chatard J-C, Busso T, Geyssant A, Barale F, Lacoste L. Effects of training on performance in competitive swimming. Canadian journal of applied physiology. 1995;20(4):395-406.

10. Hellard P, Avalos-Fernandes M, Lefort G, et al. Elite Swimmers' Training Patterns in the 25 Weeks Prior to Their Season's Best Performances: Insights Into Periodization From a 20-Years Cohort. Frontiers in physiology. 2019;10:363.

11. Toussaint HM, Beek PJ. Biomechanics of competitive front crawl swimming. Sports medicine (Auckland, NZ). 1992;13(1):8-24.

12. Sylta O, Tonnessen E, Seiler S. From heart-rate data to training quantification: a comparison of 3 methods of training-intensity analysis. Int J Sports Physiol Perform. 2014;9(1):100-107.

13. Collette R, Kellmann M, Ferrauti A, Meyer T, Pfeiffer M. Relation Between Training Load and Recovery-Stress State in High-Performance Swimming. Frontiers in physiology. 2018;9:845.

14. Dingley A, Pyne D, Youngson J, Burkett B. Effectiveness of a Dry-Land Resistance Training Program on Strength, Power, and Swimming Performance in Paralympic Swimmers. Journal of Strength and Conditioning Research. 2015;29:61Y 626.

15. Laursen PB. Training for intense exercise performance: high-intensity or high-volume training? Scandinavian journal of medicine \& science in sports. 2010;20:1-10. 